\title{
Facile synthesis and enhanced gas sensing properties of grain size-adjustable $\mathrm{In}_{2} \mathrm{O}_{3}$ micro/nanotubes
}

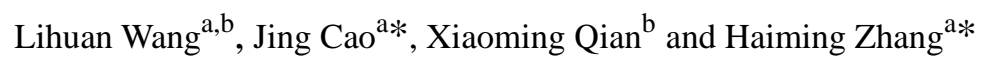

${ }^{a}$ School of Science, Tianjin Polytechnic University, Tianjin 300387, People's Republic of China;

${ }^{\mathrm{b}}$ School of Textiles, Tianjin Polytechnic University, Tianjin 300387, People’s Republic of China

\begin{abstract}
Without accurately controlling the ratio of reactants, indium oxide $\left(\operatorname{In}_{2} \mathrm{O}_{3}\right)$ micro/nanotubes are successfully fabricated by a facile coaxial electrospinning route and a subsequent annealing treatment.

The micro/nanotubes consist of $\operatorname{In}_{2} \mathrm{O}_{3}$ nanocrystals with primary grain sizes of 10-23 nm and present rough surfaces. The grain sizes of $\operatorname{In}_{2} \mathrm{O}_{3}$ micro/nanotubes can be adjusted by the calcination temperature. The $\mathrm{In}_{2} \mathrm{O}_{3}$ micro/nanotubes present grain sizes-dependent gas sensing properties. The sensors based on $\mathrm{In}_{2} \mathrm{O}_{3}$ micro/nanotubes calcined at $400{ }^{\circ} \mathrm{C}$ (NT400) show better HCHO gas sensing performances in comparison with the sensors based on $\mathrm{In}_{2} \mathrm{O}_{3}$ micro/nanotubes calcined at $600{ }^{\circ} \mathrm{C}(\mathrm{NT} 600)$ and $800{ }^{\circ} \mathrm{C}$ (NT800). The facile fabrication method and excellent gas sensing performances make as-prepared $\operatorname{In}_{2} \mathrm{O}_{3}$ micro/nanotubes developed for $\mathrm{HCHO}$ gas detection in practice.
\end{abstract}

Keywords: Semiconductors; Indium oxide; Micro/nanotubes; Sensors.

\section{Introduction}

With increasing concerns of air pollution on human health and public safety, the need for high performance gas sensors have been highlighted [1]. In order to effectively detect combustible and toxic gas, significant effects have been made in the design and engineering of novel gas sensing materials, which can be employed for highly sensitive gas sensors [2,3]. Among them, one-dimensional

* Corresponding author.

E-mail address: caojing@tjpu.edu.cn; zhmtjwl@163.com 
nanostructures have received considerable attention due to their large surface area and efficient transforming of surface chemical species into electrical signals by surface depletion layers [4-6]. $\operatorname{In}_{2} \mathrm{O}_{3}$, as an important n-type wide band gas semiconductor, has been acknowledged as a promising candidate for the application in gas sensors [7-9]. Up to now, various micro/nanostructured $\operatorname{In}_{2} \mathrm{O}_{3}$ has been prepared by different routes. In general, these approaches usually demand stringent experiment conditions or the use of catalysts/templates, which possibly limit the potential applications. In contrast, the facile coaxial electrospinning approach becomes a promising choice to solve the above problems.

In this work, $\mathrm{In}_{2} \mathrm{O}_{3}$ micro/nanotubes with different grain sizes have been successfully fabricated via a facile coaxial electrospinning technique and the subsequent annealing treatment. The as-obtained $\operatorname{In}_{2} \mathrm{O}_{3}$ micro/nanotubes are developed for $\mathrm{HCHO}$ gas detection and their sensing properties have been investigated in detail. The gas sensing results indicate that $\operatorname{In}_{2} \mathrm{O}_{3}$ micro/nanotubes with small nanograins present better $\mathrm{HCHO}$ sensing performances in comparison with $\mathrm{In}_{2} \mathrm{O}_{3}$ micro/nanotubes with large nanograins and solid $\mathrm{In}_{2} \mathrm{O}_{3}$ micro/nanofibers.

\section{Experiments}

All the reagents (analytical-grade purity) were used as purchased without further purification. $0.5 \mathrm{~g}$ PVP was dissolved in the mixed solution of $0.3 \mathrm{~mL} \mathrm{DMF}, 4.7 \mathrm{~mL} \mathrm{C}_{2} \mathrm{H}_{5} \mathrm{OH}$ and $2.5 \mathrm{ml} \mathrm{CH}_{3} \mathrm{COOH}$ under vigorous stirring for $1 \mathrm{~h}$. And then, $0.4 \mathrm{~g} \mathrm{In}\left(\mathrm{NO}_{3}\right)_{3} \cdot 4.5 \mathrm{H}_{2} \mathrm{O}$ was added into the above mixture and stirred for $4 \mathrm{~h}$ to form uniform and clear precursor solution. The obtained precursor solution was then loaded into the syringe as outer fluid, the inner fluid was paraffins. Coaxial electrospinning installation was shown in our previous report [10]. To obtain $\mathrm{In}_{2} \mathrm{O}_{3}$ nanotubes, the $\mathrm{PVP} / \mathrm{In}\left(\mathrm{NO}_{3}\right)_{3} \cdot 4.5 \mathrm{H}_{2} \mathrm{O}$ composite micro/nanofibers prepared by coaxial electrospinning were calcined in air (no inert gas protection) at $400{ }^{\circ} \mathrm{C}, 600{ }^{\circ} \mathrm{C}$, or $800{ }^{\circ} \mathrm{C}$ for $3 \mathrm{~h}$. These samples were named as "NT400", "NT600”, "NT800" 
according to calcination temperature, respectively. Micro/nanofibers (NF600) fabricated by

electrospinning (calcined at $600^{\circ} \mathrm{C}$ ) were synthesized as a reference material.

The morphology and crystal structure of the $\mathrm{In}_{2} \mathrm{O}_{3}$ micro/nanotubes were characterized by the transmission electron microscope (JEOL JEM-2200FS) and the X-ray diffraction (Rigaku D/max-Ra). The details of the sensor fabrication were similar to our previous report [10]. Briefly, $0.01 \mathrm{~g}_{2} \mathrm{In}_{3}$ nanomaterials were mixed with $0.1 \mathrm{~mL}$ deionized water to form a paste. The paste was printed on a ceramic tube. A pair of gold electrodes was previously printed on the ceramic tube to transfer electrical signal, and a Ni-Cr heating wire was inserted into the tube to form a side-heated gas sensor. The sensors were dried at $100{ }^{\circ} \mathrm{C}$ for $3 \mathrm{~h}$ and then welded on a socket. The work temperature of the sensor was controlled by work electrical current. The gas sensing properties were measured by a CGS-8 intelligent gas sensing analysis system. The sensor sensitivity was defined as $\mathrm{S}=R_{a} / R_{g}$. Here, $R_{a}$ and $R_{g}$ was the resistance of the sensor in the air and target gas, respectively. The response and recovery time was defined as the time taken by the sensors to achieve $90 \%$ of the total resistance change in the case of adsorption and desorption, respectively.

\section{Results and discussion}

Fig.1a presents SEM image of $\mathrm{In}_{2} \mathrm{O}_{3} \mathrm{NT} 400$. The tubular structure and relatively rough surfaces can be clearly seen. Fig. 1b-d shows TEM images of NT400, NT600 and NT800, respectively. The burst pipe orifice can be easily observed, which demonstrates the tubular structure of NT400, NT600 and NT800. In addition, the surfaces of three $\mathrm{In}_{2} \mathrm{O}_{3}$ micro/nanotubes are rough and nanograins of the surfaces are loose with a large number of internal spaces. Fig. 1e shows the TEM image of $\operatorname{In}_{2} \mathrm{O}_{3} \mathrm{NF600}$ and two nanofibers is clearly visible. Grain size distributions of $\operatorname{In}_{2} \mathrm{O}_{3}$ micro/nanotubes are shown in Fig. 1f. The grain size is mainly confined to $10 \mathrm{~nm}, 15 \mathrm{~nm}$ and $23 \mathrm{~nm}$ for $\mathrm{In}_{2} \mathrm{O}_{3}$ NT400, NT600 and NT800, 
respectively.

Fig. 2 shows XRD patterns of $\operatorname{In}_{2} \mathrm{O}_{3}$ NT400, NT600, NT800 and NF600. It is clearly seen from Fig. $2 \mathrm{~b}$ that all the diffraction peaks for NT400 are weak, and only five main peaks can be distinguished. With increasing calcination temperature to $600{ }^{\circ} \mathrm{C}$ (Fig. 2c) and $800{ }^{\circ} \mathrm{C}$ (Fig. 2d), the diffraction peaks become sharper, more well-defined and have higher intensity (JCPDS No.71-2195). Fig. 2a indicates $\mathrm{In}_{2} \mathrm{O}_{3}$ NF600 is well crystallized. All the diffraction peaks are well indexed to cubic $\operatorname{In}_{2} \mathrm{O}_{3}$.

Fig. 3a shows responses of $\mathrm{In}_{2} \mathrm{O}_{3}$ NT400, NT600, NT800 and NF600 toward 50 ppm HCHO at different work temperatures. Obviously, responses of four sensors are strongly dependent on the temperatures. The sensitivities are found to increase with increasing the work temperature, attain the maximum (at $240^{\circ} \mathrm{C}$ ), and then decrease with further increasing the work temperature. Sensitivities increase with the decrease of grain sizes, and $\mathrm{In}_{2} \mathrm{O}_{3} \mathrm{NT} 400$ based sensor presents highest $\mathrm{HCHO}$ sensitivity. In addition, $\mathrm{In}_{2} \mathrm{O}_{3}$ micro/nanotubes (NT600) present a higher sensitivity in comparison with $\mathrm{In}_{2} \mathrm{O}_{3}$ micro/nanofibers (NF600). The senor for practical application is required not only to have high response, but also good selectivity $[11,12]$. The responses of four sensors to $50 \mathrm{ppm}$ various gases are measured at $240{ }^{\circ} \mathrm{C}$. As shown in Fig. 3b, four sensors show obvious responses to $\mathrm{HCHO}$ and lesser effect to other gases.

Fig. 4a shows dynamic responses of NT400, NT600, NT800 and NF600 based sensors to different $\mathrm{HCHO}$ concentrations at $240{ }^{\circ} \mathrm{C}$. The responses of sensors change rapidly on being exposed to air and to HCHO. Moreover, the on- and off responses can be repeated after continuous measurement cycles, demonstrating the excellent reproducibility and stability of sensors. Fig. $4 \mathrm{~b}$ shows response-recovery curves of four sensors to $50 \mathrm{ppm} \mathrm{HCHO}$ at $240{ }^{\circ} \mathrm{C}$. It can be concluded that NT400 sensor exhibits the fastest switching dynamics to $\mathrm{HCHO}$ at the optimal temperature. That is because that the sensitivity of 
NT400 is much higher than that of NT800 but the response and recovery time of both samples are similar. As larger response values represent bigger electrical changes, so the similar time means that NT400 based sensors own faster sensing speed. In addition, the $\operatorname{In}_{2} \mathrm{O}_{3}$ NT400 sensor also shows the low concentration detection limit (1ppm). Compared with many other HCHO gas sensors [13-15], the $\operatorname{In}_{2} \mathrm{O}_{3}$ NT400 sensor presents a superior gas sensing performance, which is predominantly attributed to 1D tubular porous structure and more potential barriers, thus resulting in larger change in resistance.

\section{Conclusions}

In summary, $\mathrm{In}_{2} \mathrm{O}_{3}$ micro/nanotubes have been successfully prepared by a facile coaxial electrospinning technique. Through controlling the calcination temperature, grain sizes of $\operatorname{In}_{2} \mathrm{O}_{3}$ micro/nanotubes can be well adjusted. The $\mathrm{In}_{2} \mathrm{O}_{3}$ micro/nanotubes present grain sizes-dependent gas sensing performances. And the sensors based on $\operatorname{In}_{2} \mathrm{O}_{3}$ micro/nanotubes with small grains exhibit excellent $\mathrm{HCHO}$ gas sensing performances in terms of high sensitivity, fast response/recovery time and well stability. The current work clearly demonstrates that as-prepared $\operatorname{In}_{2} \mathrm{O}_{3}$ micro/nanotubes can be developed to be a promising high performance $\mathrm{HCHO}$ gas sensor.

\section{Acknowledgements}

This work was funded by the National Science Foundation of China, Nos. 61274064.

\section{References}

[1] Bai SL, Zhang KW, Luo RX, Li DQ, Chen AF, Liu CC. J Mater Chem 2012;22:12643-12650.

[2] Jiang XH, Ma SY, Sun AM, Xu XL, Li WQ, Wang TT, et al. Mater Lett 2015;159:5-8.

[3] Li TM, Zeng W, Miao B, Zhao SQ, Li YQ, Zhang H. Mater Lett 2015;144:106-109.

[4] Cao J, Dou HM, Zhang H, Mei HX, Liu S, Fei T, et al. Sens Actuators B 2014; 198:180-187.

[5] Li X, Zhang H, Feng CH, Sun YF, Ma J, Wang C, et al. RSC Adv 2014;4:27552-27555. 
[6] Wu HY, Kan K, Wang LL, Zhang G, Yang Y, Li H, et al. CrystEngComm, 2014;16:9116-9124.

[7] Song P, Han D, Zhang HH, Li J, Yang ZX, Wang Q. Mater Lett 2014;196:434-439.

[8] Sun XH, Ji HM, Li XL, Cai S, Zheng CM. Mater Lett 2014;120:287-291.

[9] Gong FL, Liu HZ, Liu CY, Gong YY, Zhang YH, Meng EC, et al. Mater Lett 2016;163:236-239.

[10] Cao J, Zhang T, Li F, Yang H, Liu S. New J Chem 2013;37:2031-2036.

[11] Kaneti YV, Zakaria QMD, Zhang ZJ, Chen CY, Yue J, Liu MS, et al. J Mater Chem A 2014;2:13283-13292.

[12] Du JP, Yao HL, Zhao RH, Wang HY, Xie YJ, Li JP. Mater Lett 2014;136:427-430.

[13] Zhang LX, Zhao JH, Zheng JF, Li L, Zhu ZP. Appl Surf Sci 2011;258:711-718.

[14] Lai XY, Li P, Yang TL, Tu JC, Xue P. Scr Mater 2012;67:293-296.

[15] Yang HX, Wang SP, Yang YZ. CrystEngComm, 2012;14:1135-1142.

\section{Figure Captions}

Fig. 1. (a) The SEM image of $\operatorname{In}_{2} \mathrm{O}_{3}$ NT400, (b-d) TEM images of $\operatorname{In}_{2} \mathrm{O}_{3}$ NT400, NT600 and NT800, respectively, (e) the TEM image of $\mathrm{In}_{2} \mathrm{O}_{3}$ NF600, (f) grain size distributions of NT400, NT600, NT800. The inset is the enlarged image.

Fig. 2. XRD patterns of (a) NF600, (b-d) NT400, NT600 and NT800, respectively.

Fig. 3. (a) Responses of NT400, NT600, NT800 and NF600 based sensors to 50 ppm HCHO as a function of operating temperature, (b) responses of NT400, NT600, NT800 and NF600 based sensors to $50 \mathrm{ppm}$ various testing gases at $240{ }^{\circ} \mathrm{C}$.

Fig. 4. (a) Dynamic responses of NT400, NT600, NT800 and NF600 to 5, 10, 30, 50 and 100 ppm $\mathrm{HCHO}$ at $240{ }^{\circ} \mathrm{C}$, (b) Response-recovery curves of NT400, NT600, NT800 and NF600 to 50 ppm $\mathrm{HCHO}$ at $240{ }^{\circ} \mathrm{C}$. 
Fig. 1

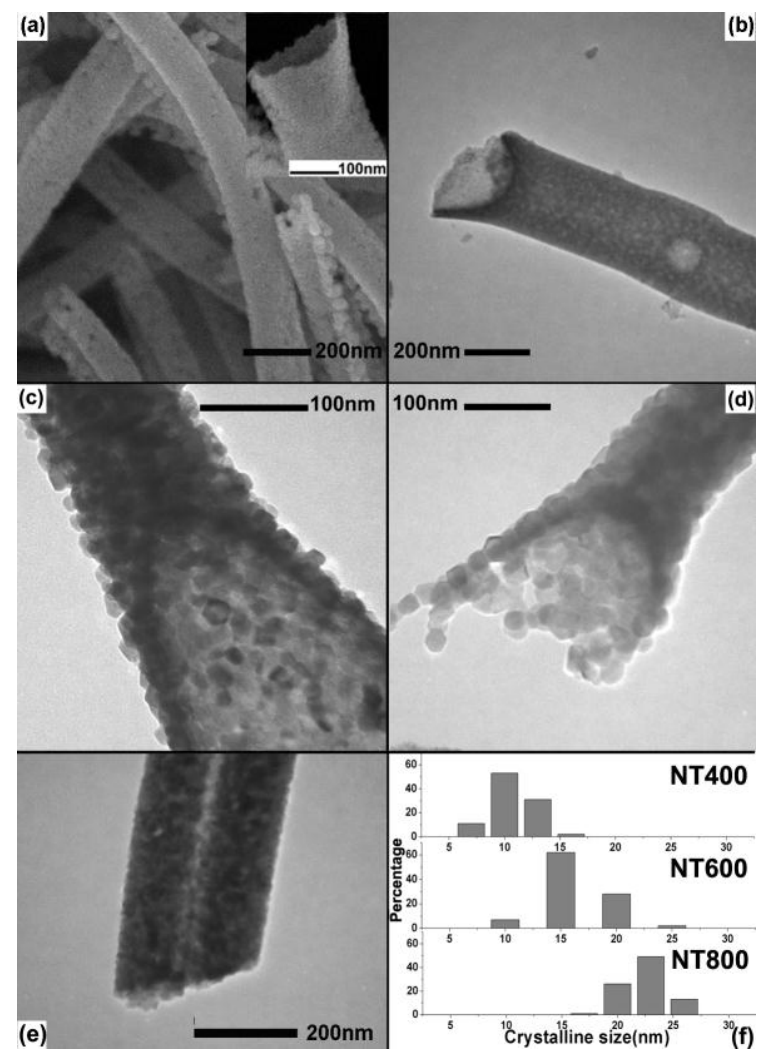

Fig. 2

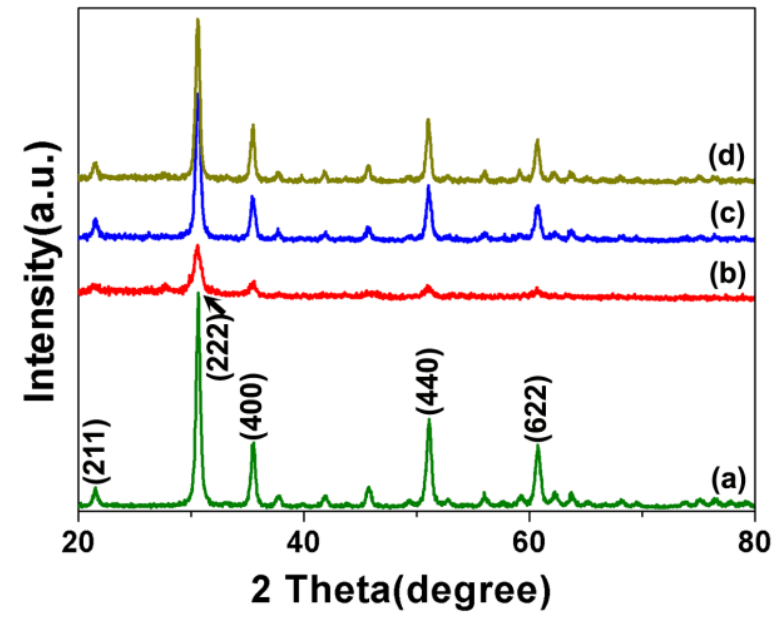


Fig. 3
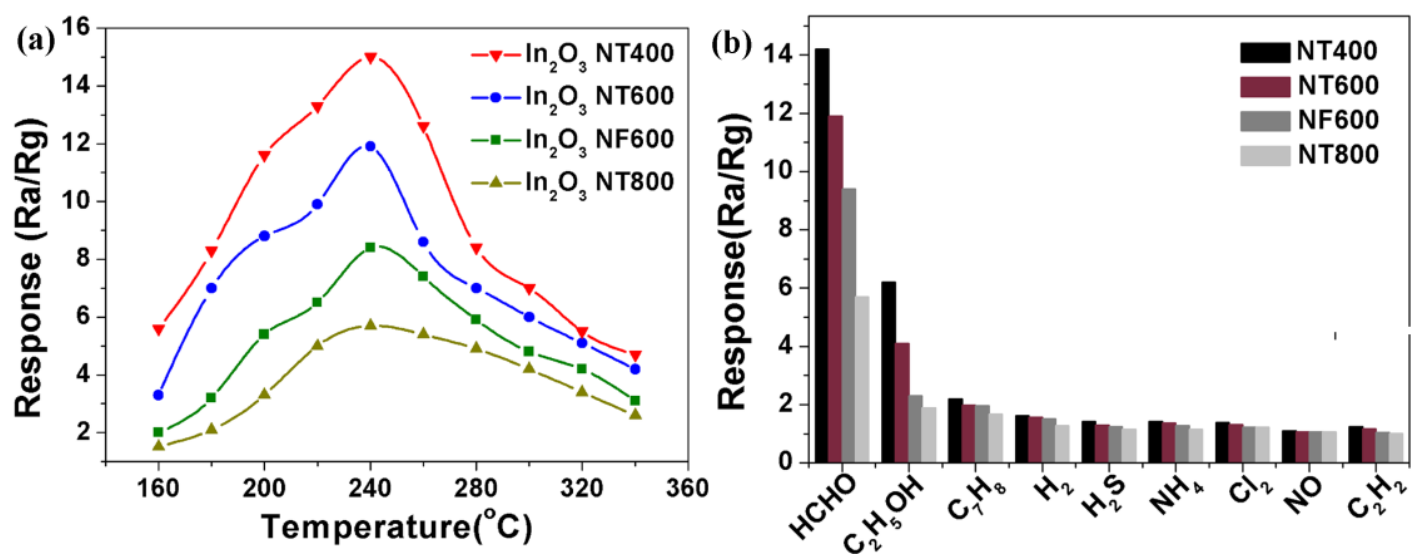

Fig. 4

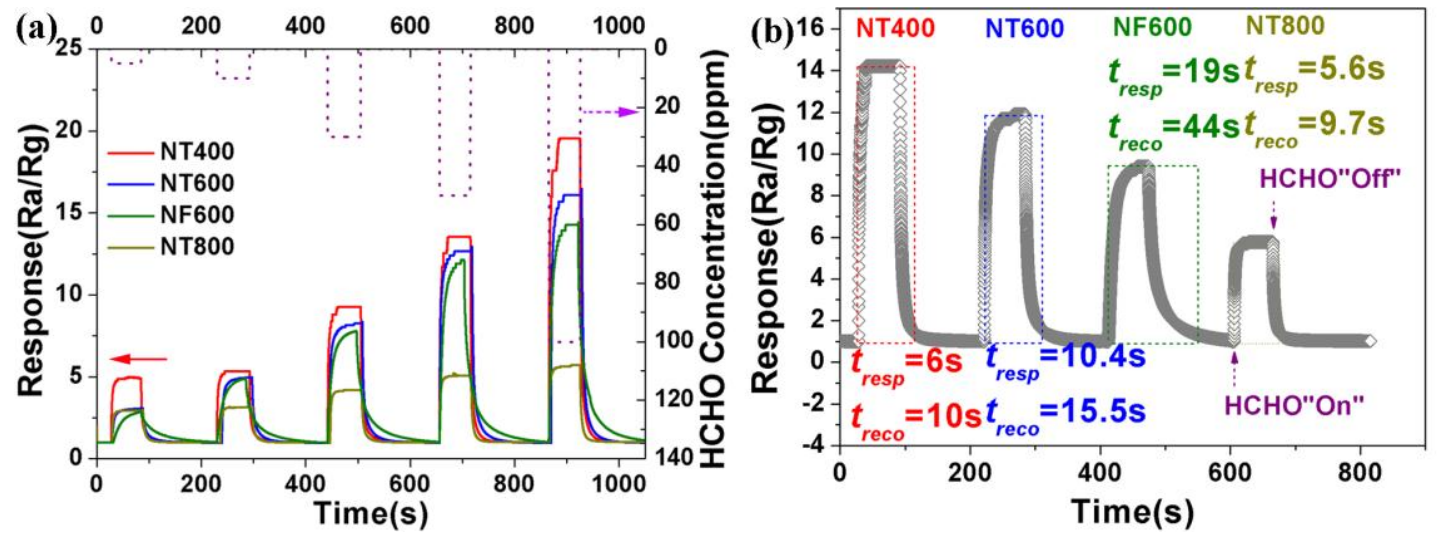

